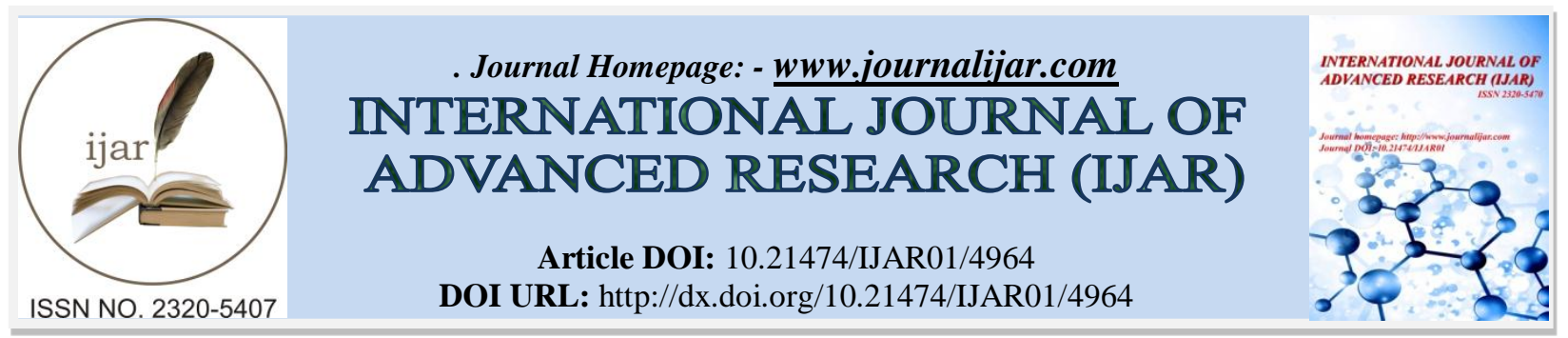

RESEARCH ARTICLE

\title{
SPECIES IDENTIFICATION INFERRED THROUGH MITOCHONDRIAL 16S rRNA GENE SEQUENCE BETWEEN FRESHWATER TESTUDINES - LISSEMYS PUNCTATA AND MELANOCHELYS TRIJUGA.
}

Lalitha $\mathbf{R}$ and *Vidya $\mathbf{R}$ Chandavar.

Molecular Endocrinology Laboratory, Department of Biotechnology, Yuvaraja's College, A Constituent Autonomous College of University of Mysore, Mysore - 570005 .

\section{Manuscript Info}

........................

Manuscript History

Received: 26 May 2017

Final Accepted: 28 June 2017

Published: July 2017

Key words:-

Hotstart PCR, DNA barcoding, 16S

rRNA, Lissemys punctata, Melanochelys

trijuga

\section{Abstract}

The molecular study of mitochondrial $16 \mathrm{~S}$ rRNA gene is the first comparative report showing molecular variations of the target gene between two freshwater terrapins- Lissemys punctata and Melanochelys trijuga. Partial 16S rRNA gene amplification was performed by hotstart PCR and sequences were acquired by bidirectional Sanger sequencing after column purification of amplicons. Interspecies comparison after sequence alignment of database species from two families along with query sequences revealed 54\% (total 918 sites) conserved regions between the families and only $44 \%$ showed variations. Intraspecies conserved/variable regions were 1359/84 and 1404/42 sites out of 1696 total positions considered respectively. The presence of consensus regions among different species indicates the scope for developing universal primers to amplify the region in various species of turtles belonging to these families. Our results highlight that $16 \mathrm{~S}$ rRNA sequences were successful in identifying and evaluating the species into their respective family Trionychidae and Geoemydidae. Hence, it is recommended to conduct similar study on these species in large numbers concentrating various geographical locations of Karnataka, India to curb wildlife crimes and conserve these species in the ecosystem.

Copy Right, IJAR, 2017,. All rights reserved.

\section{Introduction:-}

Ribosomes are the integral part of all living cellular systems, its form and function is consistent across the wide spectrum of biosphere. Significance of 16S rRNA sequence in species identification and phylogeny was pioneered in 1977, by Carl Woese who was responsible for the discovery of third domain of life. Among vertebrates, the 16S rRNA gene sequence study is used for DNA barcoding (Vences et al., 2005), species identification for forensic purposes and taxonomical studies (Jogayya et al., 2013; Yang et al., 2014). In later years there was immense study of 16S rRNA gene in various organisms; especially the contribution was significant from the field of microbiology. Microbes causing infectious and deadly diseases in animals are clinically identified based on 16S rRNA sequences and has grown into popular molecular marker for unbiased identification of pathogens compared to conventional culture based methods (Srinivasan et al., 2015).

Corresponding Author: Vidya R Chandavar.

Address: - Molecular Endocrinology Laboratory, Department of Biotechnology, Yuvaraja's College, A Constituent Autonomous College of University of Mysore, Mysore - 570005. 
There is another equivalent, extensively used mtDNA molecular marker, the COI gene, in species identification classifying the animals into various vertebrate classes (Trivedi et al., 2016), 16S rRNA has been growing equally into potential marker for species identification in reptile and amphibians (Vences et al., 2005; Jogayya et al., 2013). Apart from evolutionary studies, 16S rRNA sequencing in turtles is extended in assessment of disease causing pathogenic strains, thereby evaluating the health status in terrapins (Sakaguchi et al., 2011). The application of target gene sequencing in identifying mycobacterial strains and Salmonella species in freshwater terrapins is a well established technique (Sakaguchi et al., 2011; Back et al., 2016).

The two freshwater chelonian species Lissemys punctata (Indian flapshell/softshell turtle) (Bhupathy et al., 2014) and Melanochelys trijuga (Indian black turtle) (Das and Bhupathy, 2009) belongs to two different families Trionychidae and Geoemydidae respectively. They are widely distributed in southern Asia and south-east Asian regions, sharing the same habitat and diet but, differ in their morphology, physiology and longevity. Present study focus on variations and conserved regions of 16S rRNA gene between the species. Although these species are classified as low risk /least concerned category by IUCN, there is plenty of illegal trade reported by media and by handful of research articles in last few years, there is urgent need for extensive molecular marker study to curb these unlawful activities and take suitable measures to conserve these species in the ecosystem. The current 16S rRNA sequence data of L. punctata and M. trijuga represents the chelonian population from freshwater bodies of Mysore, Karnataka, India.

\section{Materials and Methods:- \\ Sample collection:-}

Permission to obtain biological sample from the turtle species to conduct the current scientific research is obtained from Principal Chief Conservator of Forest (Wildlife) (PCCF) and Chief Wildlife Warden, Bangalore, Karnataka, India vide letter no. $\mathrm{D} / \mathrm{WL} / \mathrm{CR} / 149 / 2010$ and $\mathrm{PS} / \mathrm{WL} / \mathrm{CR} / 21 / 2013$. Accordingly, the turtle species L. punctata $(\mathrm{n}=8)$ and $M$. trijuga $(\mathrm{n}=8)$ were captured from different natural freshwater bodies located near Mysore, Karnataka, India, at different time for peripheral whole blood collection from their hind limb femoral vein using BD vacutainers (lithium/sodium heparin coated). Animals were released to their habitat without any harm after medicating the spot of collection.

\section{Extraction of genomic DNA, PCR and Sanger sequencing technology to obtain the sequences:-}

Genomic DNA was extracted from $0.3 \mathrm{ml}$ blood carried in lysis buffer from the field, the very next day in the lab using conventional solvent based method as in (Sambrook et al., 1989). Final DNA pellets were stored in TE buffer in $-20^{\circ} \mathrm{C}$ deep chest freezer as stock for future use.

The amplification of partial 16S rRNA gene from two DNA samples was performed using hot start PCR technology (Paul et al., 2010) (JumpStart Taq Ready mix, Sigma Aldrich. Co. LLC, Bangalore, India) in order to avoid nonspecific amplification. Each fragment amplification was performed in reaction volume of $50 \mu 1$ consisting $-19 \mu 1$ milliQ , Jumpstart ready mix $(25 \mu \mathrm{l}), 1 \mu \mathrm{l}$ each of $0.2 \mu \mathrm{M}$ forward and reverse primer, $4 \mu \mathrm{l}$ diluted template DNA. The designed primers used in the amplification of $16 \mathrm{~S}$ rRNA from two species are listed in Table 1 . Thermal cycling profile was set in Applied Biosystems Veriti ${ }^{\mathrm{TM}} 96$ well cycler as - initial denaturation $95^{\circ} \mathrm{C}(1 \mathrm{~min})$, followed by 45 cycles of denaturation $95^{\circ} \mathrm{C}(30 \mathrm{sec})$, respective annealing temperature $(1 \mathrm{~min})$, extension $72^{\circ} \mathrm{C}(2 \mathrm{mins})$ with 1cycle of final extension at $72^{\circ} \mathrm{C}(10 \mathrm{mins})$ and hold on $4^{\circ} \mathrm{C}$. The PCR amplicons were examined on ethidium bromide stained $2 \%$ agarose gel in $1 \mathrm{x}$ TAE run buffer at $100 \mathrm{~V}$ for 30 mins. Further, the amplicons were subjected to column purification and bidirectional Sanger sequencing by (Chromous Biotech Pvt. Ltd, Bangalore, India).

\section{Results:-}

The sequence fragments of $16 \mathrm{~S}$ rRNA were aligned separately with their reference sequences from the database (NC_012414.1) for L. punctata samples and (HM040951.1) for M. trijuga samples respectively. In order to avoid overlapping fragment and to get single contig, the fragments were submitted to CAP3 sequence assembly program (http://doua.prabi.fr/software/cap3) (Huang and Madan, 1999) before its alignment. Few other Trinoychidae species (AF366350.1, AY962573.1, KY100866.1, JF966197.1, HQ709384.1) and Geoemydidae species (EF067858.1, JF742646.1, HM132059.1, DQ453753.1, HM131942.1, DQ659152.1, EU809939.1, NC_022857.1, EU708434.1) were collected from NCBI database for comparative study and to know sister group relationship through phylogenetic tree construction. All the above sequences along with reference and query ( $8+8$ each) sequences were aligned using online tool MUSCLE (EMBL-EBI) (Edgar, 2004) viewed and edited in BioEdit v7.2.5 (Hall, 1999) 
(Fig 1). A phylogenetic Neighbour Joining tree was constructed using K2P distance model and nucleotide statistics was calculated in MEGA v.6.06 (Tamura et al., 2013) using the aligned sequences (Fig 1).

An average length of 1404 bps (L. punctata, $\mathrm{n}=8$ ) and 1438 bps $(M$. trijuga, $\mathrm{n}=8$ ) of $16 \mathrm{~S}$ rRNA gene was successfully amplified using primer pairs (Table 1). From total 1696 aligned positions (Fig 1), 918 sites were conserved, 749 sites were variable, 530 were parsimony informative sites and 207 singleton sites were identified in MEGA v6.06 (Tamura et al., 2013). The edited fragment were subjected to similarity search in NCBI-BLAST algorithm (Johnson et al., 2008) with non- redundant nucleotide database, they revealed $97 \%$ and $99 \%$ identity respectively with their reference sequences of database. The intraspecific variations between query sequences and respective reference sequence reveal that $M$. trijuga showed less variations compared to that of L. punctata (Fig 2). The evolutionary history of 32 sequences (531 positions) was inferred by NJ tree (Saitou and Nie, 1987) with K2P distance model (Kimura, 1980) using MEGA v.6.06 (Tamura et al., 2013), it revealed closer relationship with database reference sequence of L. punctata (NC_012414.1) and M. trijuga (HM040951.1), confirms that query sequences (Lp1-8 and Sp1-8) belong to genus Lissemys and Melanochelys of family Trionychidae and Geoemydidae respectively. The substantial morphological difference between the L. punctata and M. trijuga was supported by $16 \mathrm{~S}$ rRNA sequence data which phylogenetically divided the turtle species into two major clades- hard shell turtles and soft shell turtles. Also a sister group relationship of M. trijuga with Cyclemys atripons and L. punctata with Pelodiscus sinensis was evident from the tree, although their exist few morphological dissimilarities, at one look they appear similar, so there are chances of misidentification possible but, 16S rRNA sequencing was able to resolve the species into respective genus.

Table 1:- Primer pairs used to amplify 16S rRNA gene sequence from two species of turtles.

\begin{tabular}{|c|c|c|c|c|c|}
\hline \multicolumn{7}{|c|}{ L. punctata } & Tength & Tm & Ta & $\begin{array}{c}\text { Amplicon } \\
\text { size (bps) }\end{array}$ & Reference \\
\hline F1- GTATAGGCGATAGAAAGAAAAACTGG & 26 & 59 & 52 & $572-600$ & New \\
R1- AAGAGAAGTTGCCTCTGTACTCATTT & 26 & 60 & & & New \\
\hline F2- AAAGGTAGCGTAATCACTTGTCTTTT & 26 & 60 & 55 & $564-595$ & New \\
R2- CGTATATAATGTTGGCCTCATCTTTT & 26 & 60 & & & \\
\hline F3- TCTCTTCCCGCAAGCTTAAT & 20 & 59 & 55 & $222-250$ & Engstrom et al., \\
R3- GGCAGGCATCACCCTTAATA & 20 & 59 & & & 2007 \\
\hline \multicolumn{7}{|c|}{ M. trijuga } & & & \\
\hline F1- AAAGCATTCAGCTTACACCTGA & 22 & 57.2 & 55 & $960-1038$ & 2008 \\
R1- AAGTTCCACAGGGTCTTCTCG & 21 & 58.3 & & & New \\
\hline F2- CGCCTGTTTATCAAAAACAT & 20 & 58.2 & 55 & $580-605$ & \\
R2- CTCCGGTTTGAACTCAGATC & 20 & 60.2 & & & \\
\hline F3- TAGAATGAATGGCCAAACGA & 20 & 59 & 55 & & \\
R3- TCAGATCACGTGGGACTGTT & 20 & 59 & & & \\
\hline
\end{tabular}

Figure 1:- Multiple sequence alignment of $16 \mathrm{~S}$ rRNA gene sequence of query sequences, reference sequences and other Trionychidae and Geoemydidae species extracted from NCBI database. Dots (.) represent the consensus 
sequences, variations denoted by respective nucleotides (A, T, G or C) and hyphen represents (-) gaps or missing data

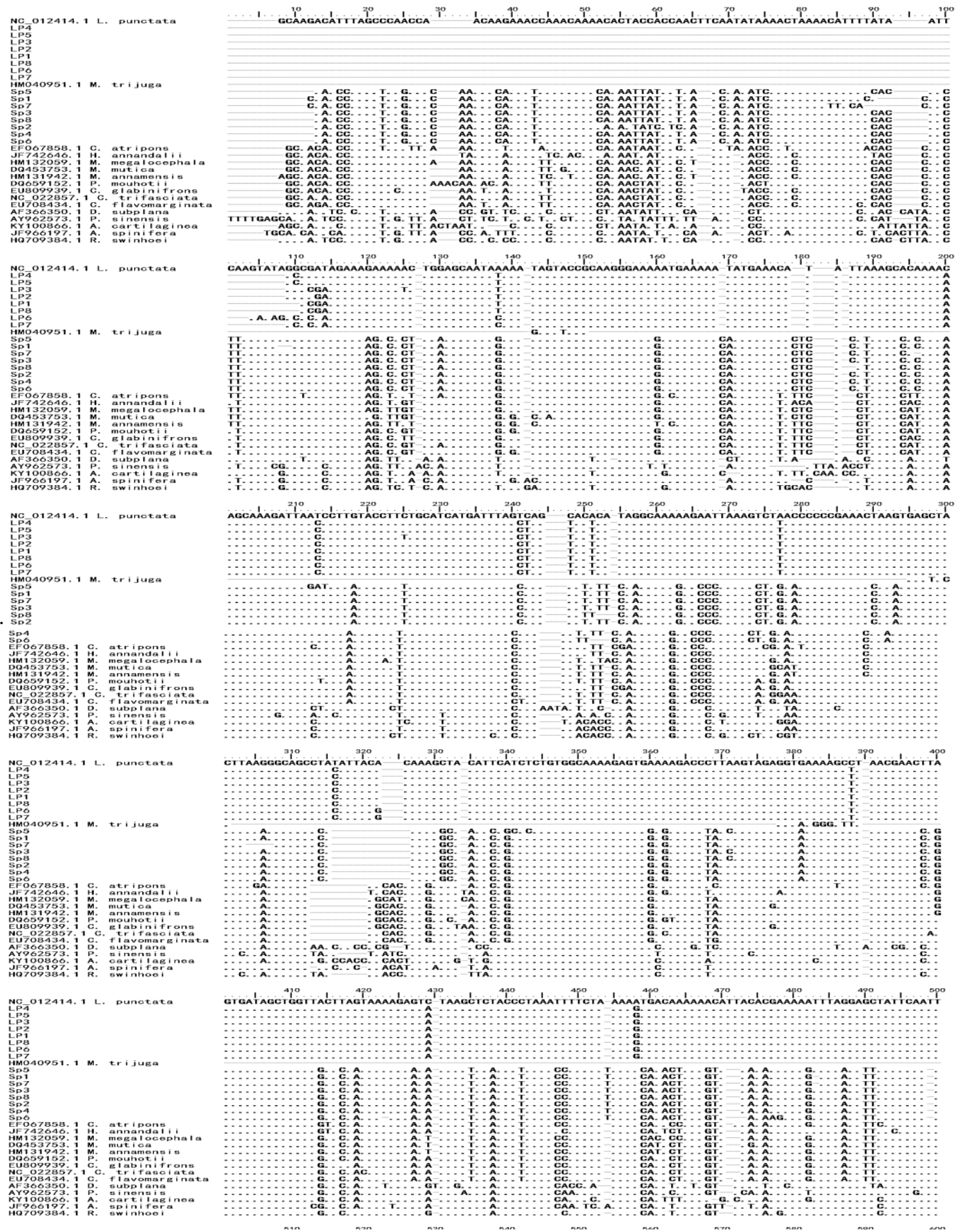



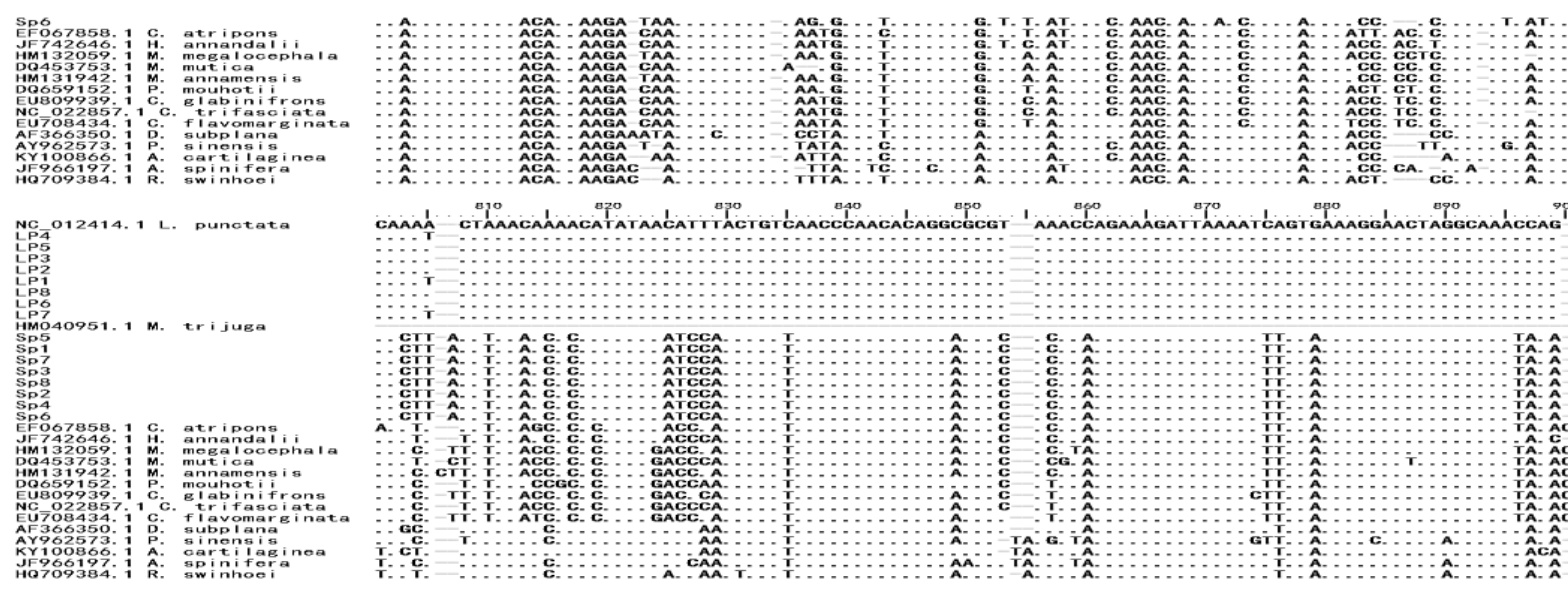

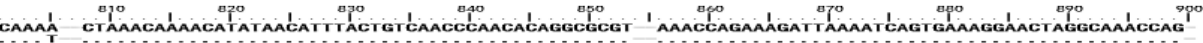
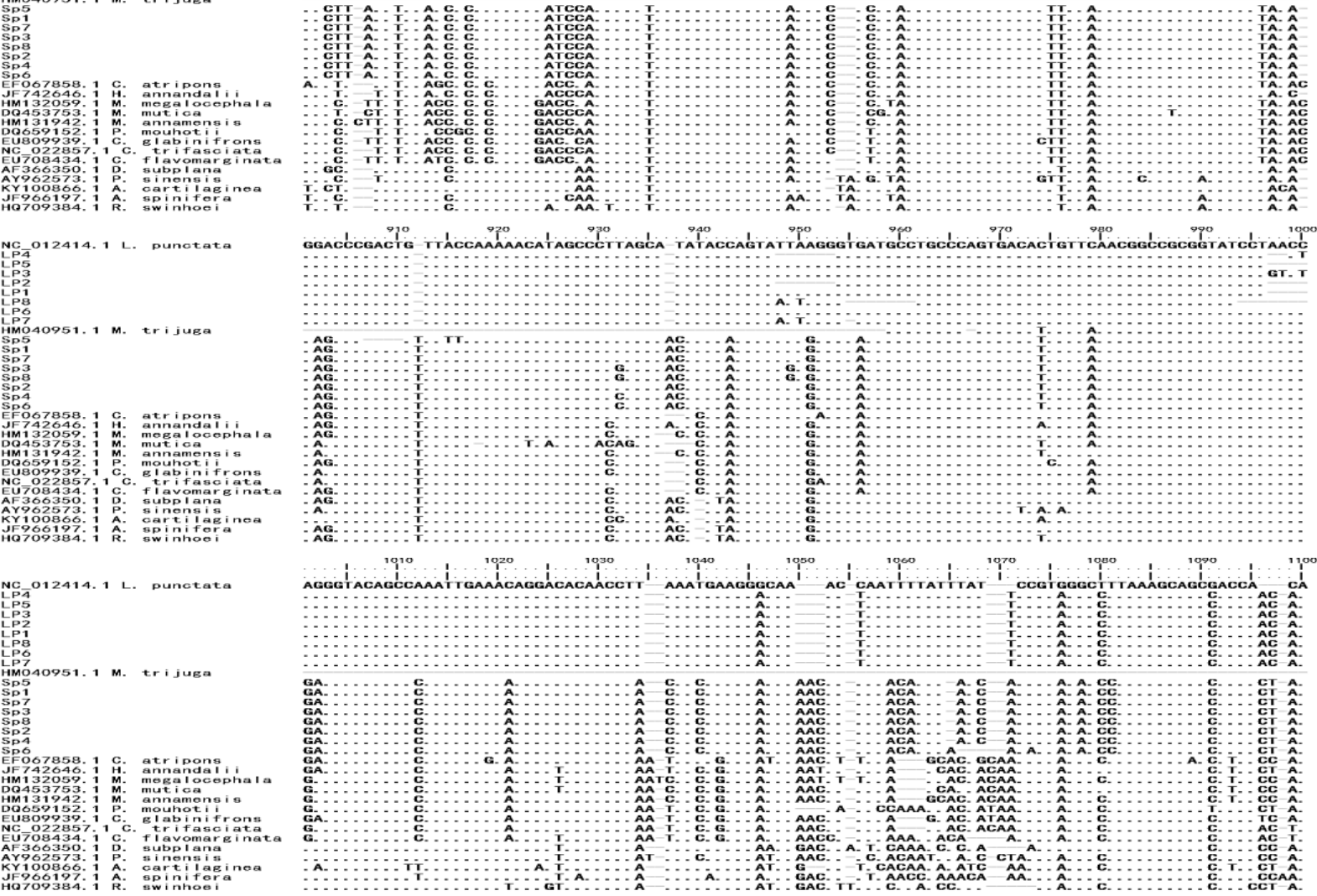

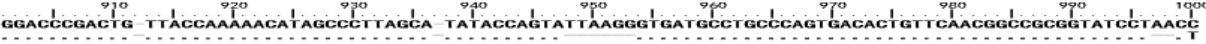
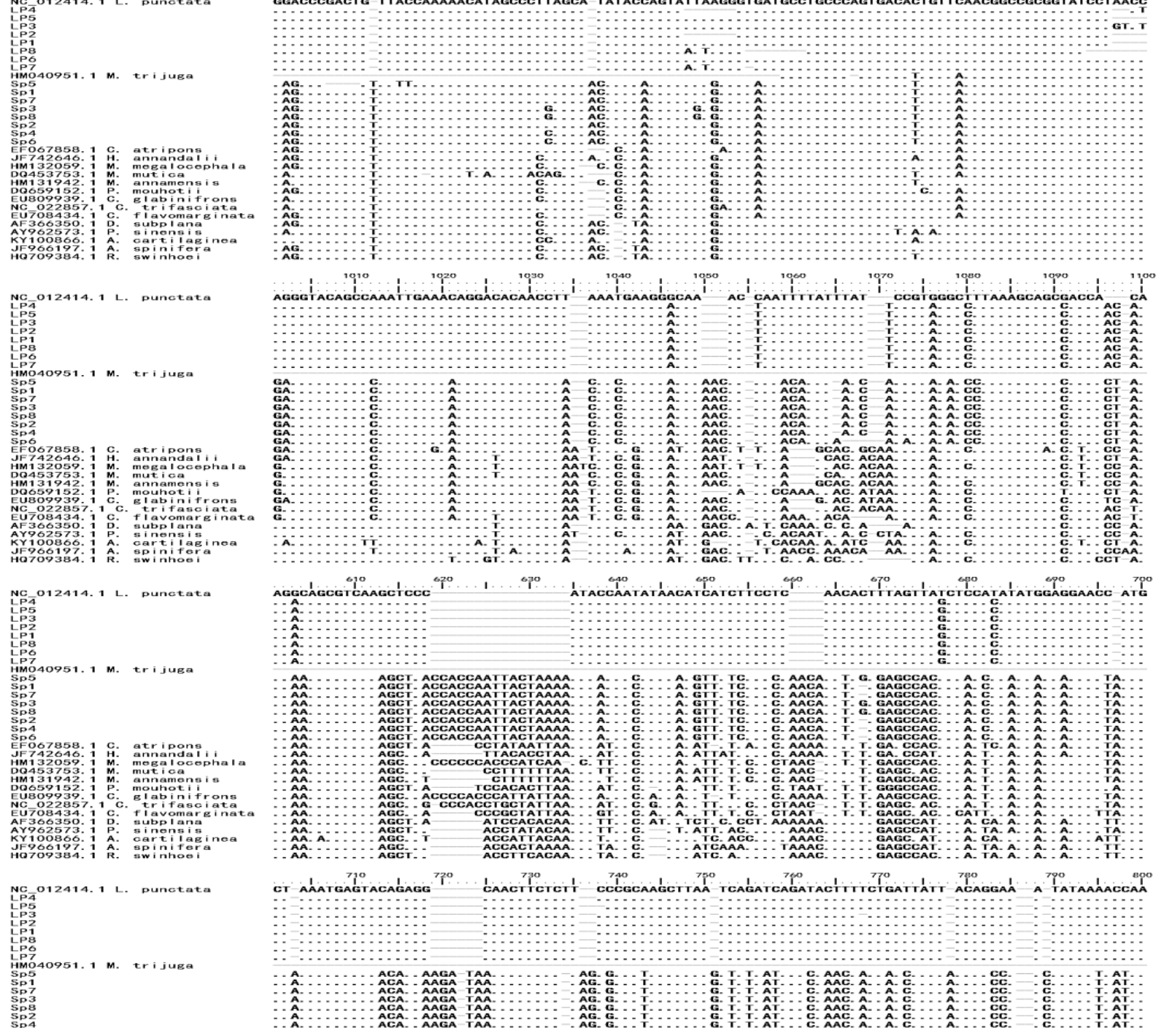

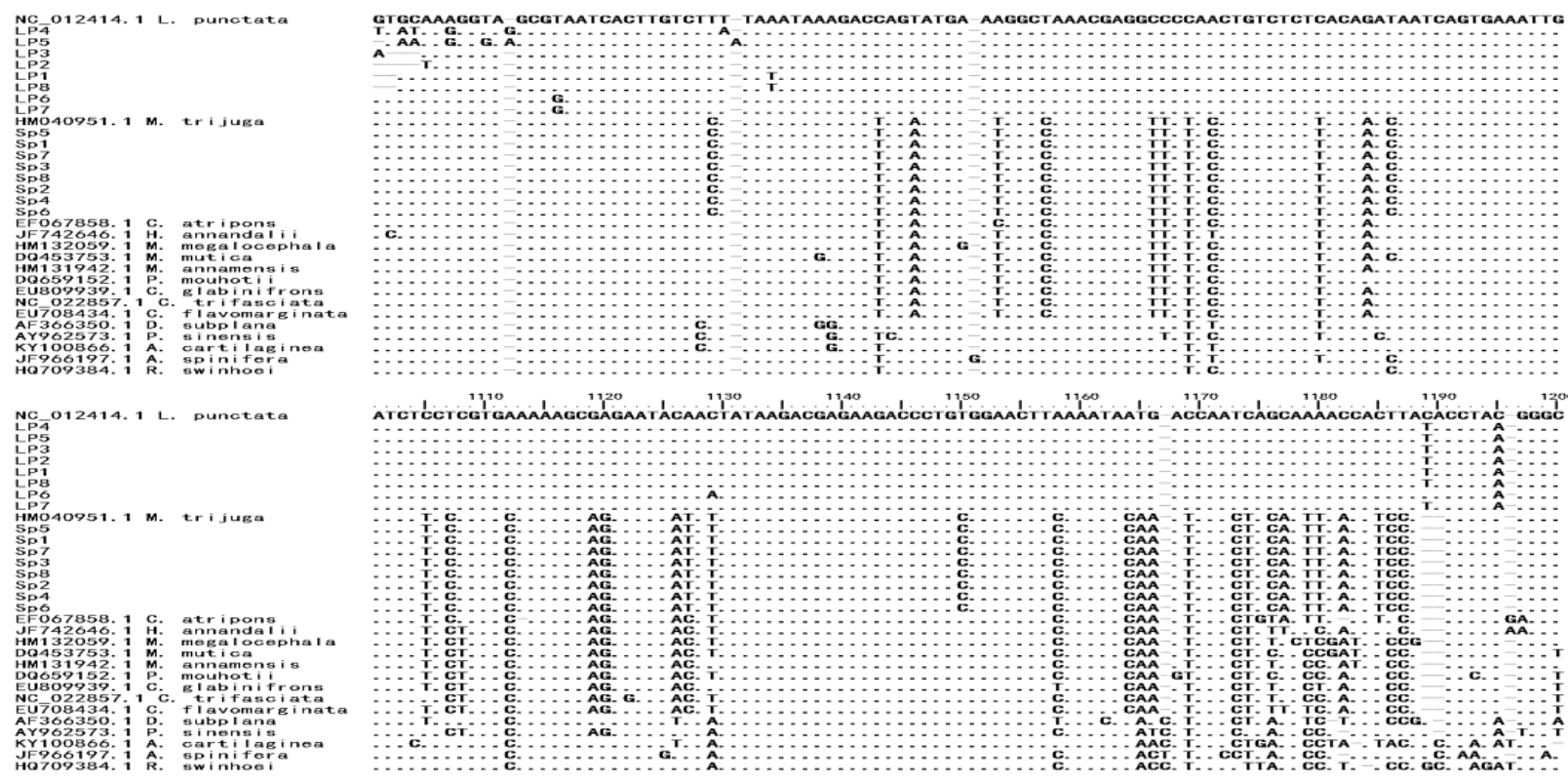

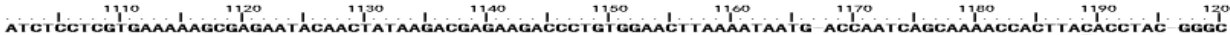
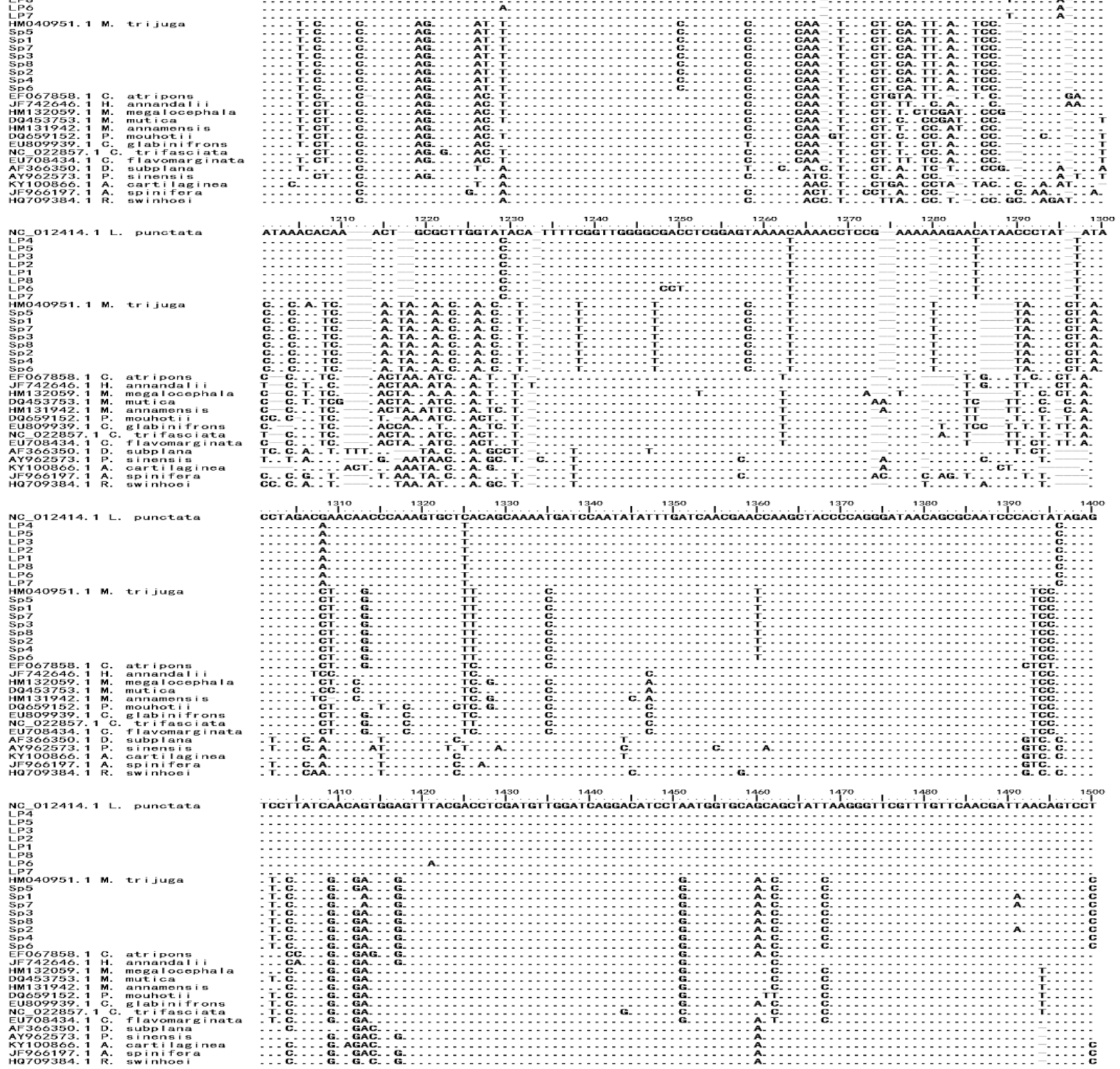

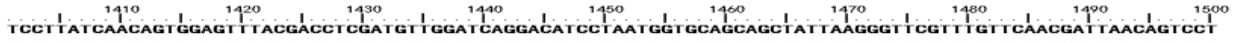

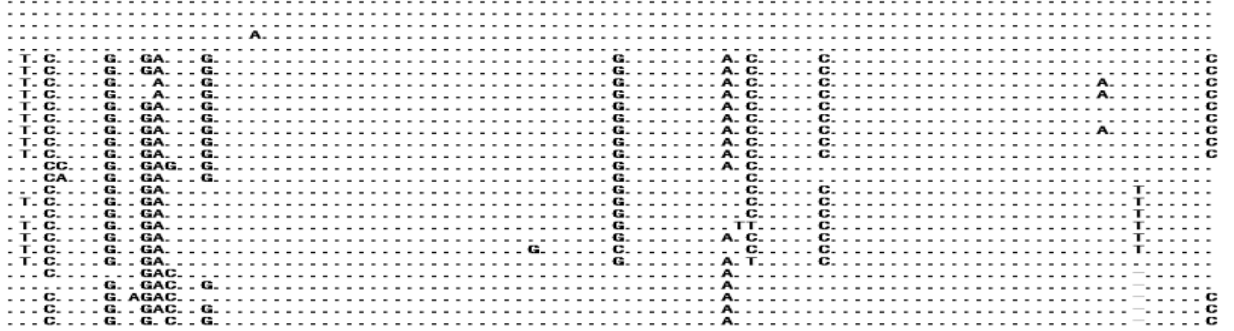

NC 012414. 1 L. punctata

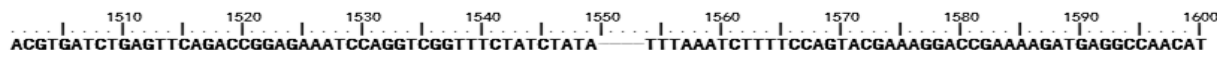



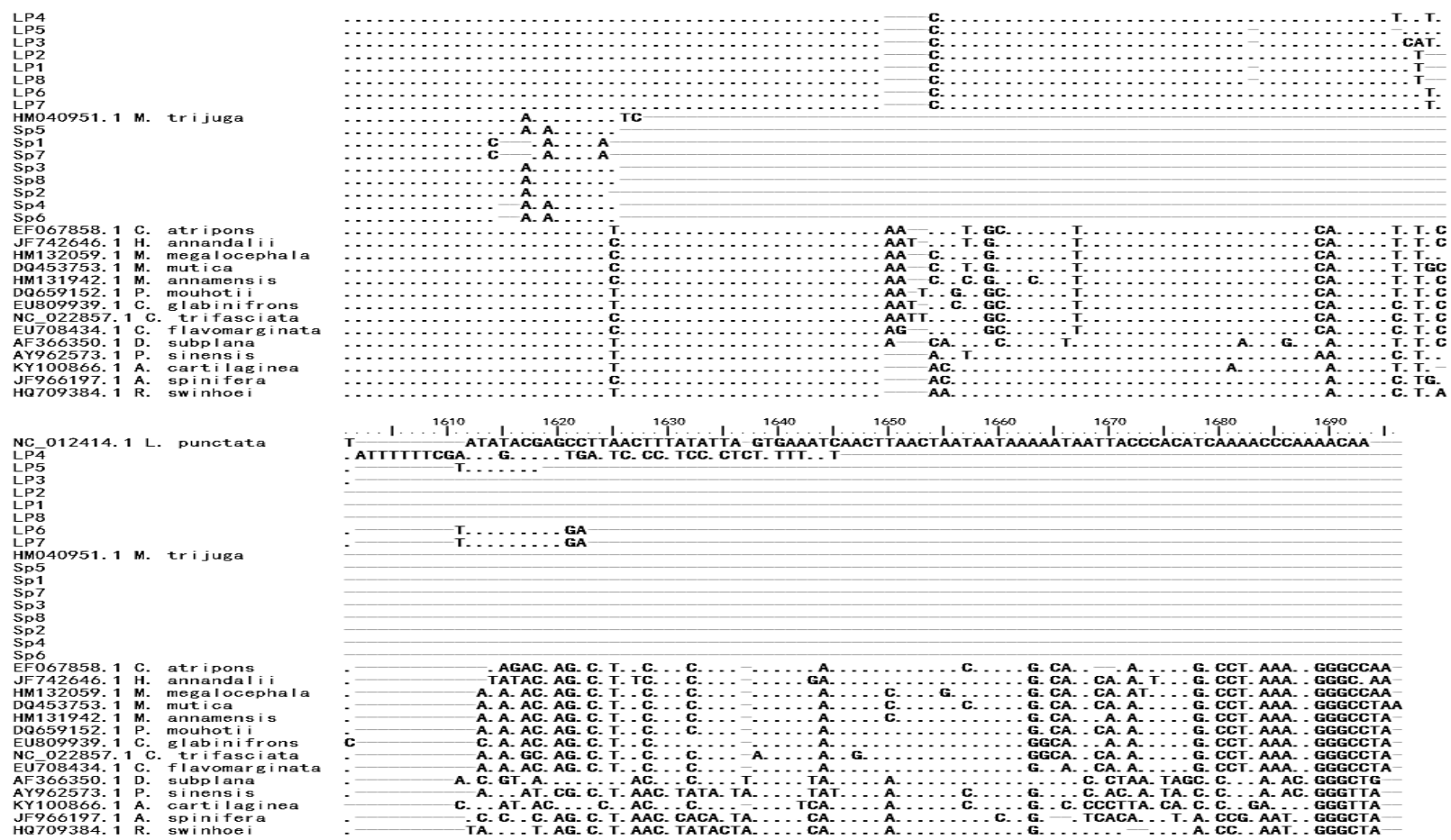

Figure 2:- Graph depicting intraspecific variation of 16S rRNA gene (Total-1696 sites) in two turtles separately showing number of conserved sites $(\mathrm{C})$, variations $(\mathrm{V})$, parsimony informative sites $(\mathrm{PI})$ and singleton sites $(\mathrm{S})$ calculated using MEGA v.6.06.

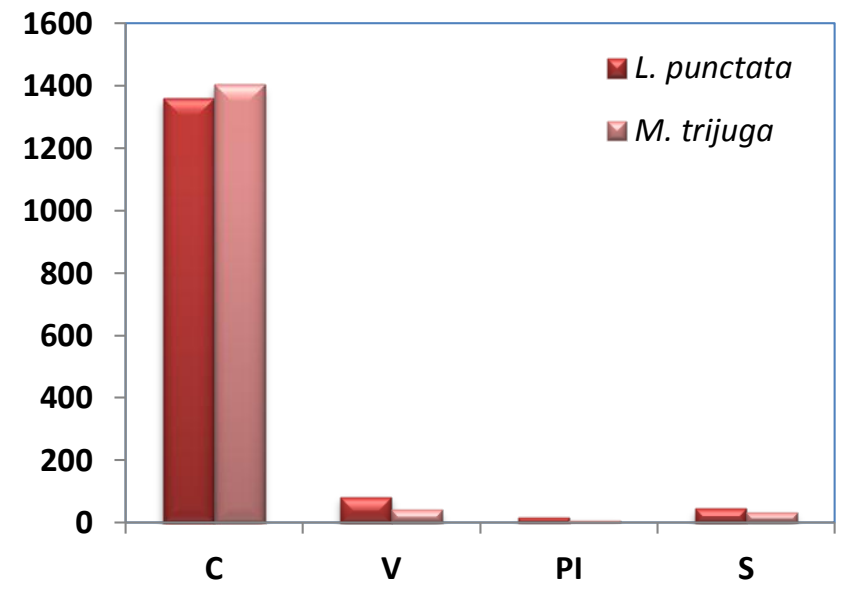

Figure 3:- Phylogenetic tree construction uses Neighbor-Joining method with K2P distance model (MEGA v6.06). The optimal tree with the sum of branch length $=0.58516771$. Only 531 positions were considered, all gaps and missing data were eliminated for tree building. 


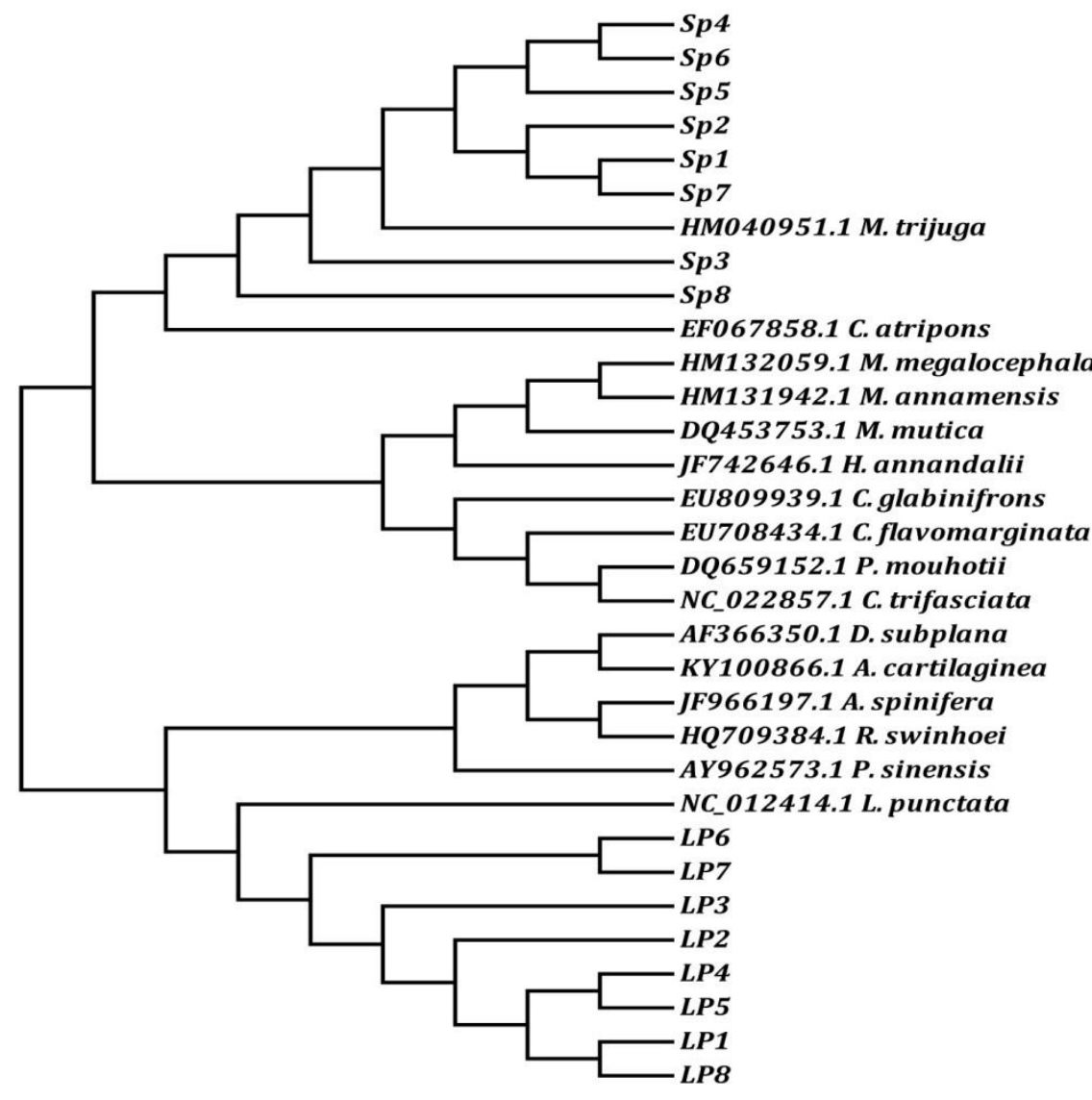

Hard shell turtles
(Geoemydidae)

Soft shell turtles

(Trionychidae)

\section{Discussions and Conclusion:-}

In the present study partial mitochondrial 16S rRNA gene sequence is able to successfully identify the species at its genus and family level, indicates the target gene can become a potential molecular marker for DNA barcoding in turtle species identification, although it was not the situation when PCR-RFLP method adopted by (Rohilla and Tiwari, 2008), were it was less decisive in resolving evolutionary relationship among freshwater turtles. A comparative performance study in species identification using COI and 16S rRNA sequence in amphibians by (Vences et al., 2005) proved that 16S rRNA was more decisive in amphibians and vertebrates in general. The more conserved regions in 16S rRNA gene compared to that of protein coding genes (COI or cytb) of mitochondria and high mutation accumulation at variable loop region of rRNA are other reasons to consider 16S rRNA a better complement in DNA barcoding for vertebrates (Vences et al., 2005). Also identification of consensus regions between two families, reveal the chances to design ubiquitous primers that can amplify the target region and sequence variations analyzed using bioinformatic tools will aid in species identification of Trionychidae and Geoemydidae as suggested by (Kitano et al., 2007). The partial sequences of 16S rRNA obtained from L. punctata and M. trijuga of current study can be accessed from NCBI database using Accession No. MF446947 to MF446953 for L. punctata samples and MF446954 to MF446959 for M. trijuga samples.

\section{Acknowledgements:-}

We are grateful to Department of Science and Technology-SERB division for sanctioning the project (No. DSTSERB/SB-EMEQ-124/2013) for conducting genomic studies in present turtle species. Sincere gratitude to DSTINSPIRE team for granting financial support to the first author throughout completion of research.

\section{References:-}

1. Back, D. S., Shin, G. W., Wendt, M. and Heo, G. J. (2016): Prevalence of Salmonella spp. in pet turtles and their environment. Lab. Anim. Res., 32(3): 166-170. 
2. Bhupathy, S., Webb, R. G. and Praschag, P. (2014): Lissemys punctata (Bonnaterre 1789)-Indian flapshell turtle. Conservation Biology of Freshwater Turtles and Tortoises. Chelonian Research Foundation., 5: 076.1076.12 .

3. Das, I. and Bhupathy, S. (2009): Melanochelys trijuga (Schweigger 1812) - Indian black turtle. Conservation Biology of Freshwater turtles and Tortoises. Chelonian Research Foundation., 5: 038.1-038.9.

4. Edgar, R. C. (2004): MUSCLE: multiple sequence alignment with high accuracy and high throughput. Nucl. Acid. Res., 32(5): 1792-1797.

5. Engstrom, T. N., Edwards, T., Osentoski, M. F. and Myers, E. M. (2007): A Compendium of PCR primers for mtDNA, Microsatellite, and other nuclear loci for freshwater turtles and tortoises. Chelonian Research Monographs., 4: 124-141.

6. Hall, T. A. (1999): BioEdit: a user friendly biological sequence alignment editor and analysis program for Windows 95/98/NT. Nucl. Acid. Symp. Ser., 41: 95-98.

7. Huang, X. and Madan, A. (1999): CAP3: A DNA sequence assembly program. Genom. Res., 9: 868-877.

8. Jogayya, K. N., Meganathan, P. R., Dubey, B. and Haque, I. (2013): Mitochondrial 16S ribosomal RNA gene for forensic identification of crocodile species. J. Forensic. Leg. Med., 20: 334-338.

9. Johnson, M., Zaretskaya, I., Raytselis, Y., Merezhuk, Y., McGinnis, S. and Madden, T. L. (2008): NCBI BLAST: a better web interface. Nucl. Acid. Res., 36: W5-W9.

10. Kimura, M. (1980): A simple method for estimating evolutionary rate of base substitutions through comparative studies of nucleotide sequences. J. Mol. Evol., 16: 111-120.

11. Kitano, T., Umetsu, K., Tian, W. and Osawa, M. (2007): Two universal primer sets for species identification among vertebrates. Int. J. Legal. Med., 121: 423-427.

12. Paul, N., Shum, J. and Le, T. (2010): Hot start PCR. Methods. Mol. Biol., 630: 301-318.

13. Rohilla, M. S. and Tiwari, P. K. (2008): Restriction fragment length polymorphism of mitochondrial DNA and phylogenetic relationships among five species of Indian freshwater turtles. J. Appl. Genet., 49(2): 167-182.

14. Saitou, N. and Nei, M. (1987): The neighbor-joining method: A new method for reconstructing phylogenetic trees. Mol. Biol. Evol., 4: 406-425.

15. Sakaguchi, K., Iima, H., Hirayama, K., Okamoto, M., et al. (2011): Mycobacterium ulcerans infection in an Indian flap-shelled turtle (Lissemys punctata punctata). J. Vet. Med. Sci., 73(9): 1217-1220.

16. Sambrook J., Fritsch E. F. and Maniatis T. (1989): Molecular cloning, A laboratory manual. $2^{\text {nd }}$ Ed. Cold Spring Harbor Laboratory, Cold Spring Harbor, New York.

17. Srinivasan, R., Karaoz, U., Volegova, M., MacKichan, J., et al. (2015): Use of 16S rRNA gene for identification of a broad range of clinically relevant bacterial pathogens. PLoS One., 10(2): e0117617.

18. Tamura, K., Stecher, G., Peterson, D., Filipski, A. and Kumar, S. (2013): MEGA6: Molecular Evolutionary Genetics Analysis version 6.0. Mol. Biol. Evol., 30: 2725-2729.

19. Trivedi, S., Aloufi, A. A., Rehman, H., Saggu, S. and Ghosh, S. K. (2016): DNA barcoding: Tool for assessing species identification in Reptilia. J. Entamol. Zool. Stud., 4(1): 332-337.

20. Vences, M., Thomas, M., van der Meijden, A., Chiari, Y. and Vieites, D. R. (2005): Comparative performance of the 16S rRNA gene in DNA barcoding of amphibians. Front. Zool., 2: 1-12.

21. Yang, L., Tan, Z., Wang, D., Xue, L., et al. (2014): Species identification through mitochondrial rRNA genetic analysis. Sci. Rep., 4: 4089. 